\title{
A GENRE-BASED TEXTUAL ANALYSIS OF EXPERT ONLINE REVIEWS OF ELECTRIC GUITAR FUZZ PEDALS
}

\author{
Ché Moya \\ Central Michigan University, USA \\ moyalc@cmich.edu
}

\begin{abstract}
This study uses genre analysis to analyze contemporary online text. Through an analysis of the linguistic features of text from a highly specialized discourse community, perceived expert online reviews of electric guitar fuzz pedals, findings from this study provide insight into the relevance of online reviews. Although there is a layman quality to the actual production of the textual online reviews, genre analysis reveals hybridized genres, authorial power within occluded genre chains, subconscious marketing techniques, and manipulation of perceived expert online reviews. Findings from this study indicate that online reviews have complex occluded genre chains, which are not readily obvious when the reviews are read only for entertainment purposes. This research has real world applications as relationships between textual generic qualities of online reviews and consumer spending habits are now easily acquired from online data-mining techniques to assist in targeting online consumers' habits and to increase sales. Online reviews are now what consumers use to assist in shopping. Control of reviews translates to control of consumers' shopping habits.
\end{abstract}

Keywords: genre analysis, discourse, review.

\section{Introduction}

The acoustic qualities of fuzz pedals have become a distinctive sound of contemporary rock music. The fuzz distortion sound originated as an emulation of a "broken" amplifier speaker, which resulted in a square sine wave for an electric guitar's signal path. The invention of "pedals" which could produce the desired fuzz distortion effect began in the early 1960s. Today the pedal industry has expanded to produce multitudes of ever more craftily engineered versions of the fuzz pedal.
(See figures 1 and 2 for examples of fuzz pedals).

The higher prices and demand for some fuzz pedals, coupled with their collectability, make them the kind of item that shoppers carefully evaluate before buying, and this has caused online reviews of fuzz pedals to gain in popularity in recent years. The expert, or for purposes of this study one should think "perceived expert," online review is similar to the movie-critic review. In a review, the reviewer has the means to use the fuzz pedal and give an assessment of its features. With online reviews, however, the "experts" may 
not be who they say they are. Because of the anonymity of the internet, there is no way to discern if an "expert" reviewer is a paid actor in the employ of the manufacturer, a genuine independent reviewer of the fuzz pedal, or somewhere in between. These reviews have the potential to save a consumer time and money, or if manipulated, can be used to sway consumers' spending habits toward a company's own products. User generated reviews, such as one might find on Amazon.com, function similarly, but can be considered a different genre; they are usually shorter in word count, of a more conversational register, and accompanied with a star rating system.

This study made use of online reviews that are based on a "producttesting" model. The reviews are situated in a format wherein a reviewer (the perceived expert) will obtain a certain fuzz pedal, then actively test the pedal (and possibly produce a video of this testing procedure), then write a review of the qualities of the pedal. Some online reviews are also accompanied with an oral account of a summary of the review process within the video, while others lack the video component entirely. All of the reviews in this research, however, contained written texts.

Before the Internet, not everyone was able to voice their opinion as a perceived equal among many. Only a select few had the means to have their opinion heard by many, for example, writers or critics of certain print publications. Online reviews have caused that paradigm to change. The power of online discourse communities has taken the word-of-mouth (WOM) review and made possible anyone who wants to communicate and has the means to access the Internet to be an online reviewer. Access to these online reviews is virtually unlimited and available at all times to those who are online.

This study provides a genre analysis of current (2010 -2015) online text of fuzz pedal reviews. Although there now exists a field of genre analysis techniques concerning product reviews, to this writer's knowledge, none exists concerning guitar fuzz pedal reviews. The new digital technology of the online fuzz pedal reviews allows for a new type of genre, and thus a new type of genre research. I take generic textual analysis, which is usually acquainted with academia, into new territory and apply it to the "expert" online review. Swales (1990, 2004) conceived and expanded on an exhaustive amount of information regarding genre analysis for academic texts. Swales' work was built upon that of Bakhtin (see Bakhtin 1979) who discussed the genres that are evident in everyday speech and communications.

Expert online reviews for electric guitar fuzz pedals are predominantly an enthusiast's topic, with those outside of this community not easily understanding the jargon and there being no explicit rules for writing them. The discourse community of fuzz pedals reviewers allows considerable room for discussion of the linguistic nature of expert online reviews. On the surface, the reviews are entertaining and informative. However, as with many human endeavors, there are several possible rationales for the language found in them. A creation of a new genre, however, does not grow from nothingness, and the language of the reviews retains echoes of the "ancestral" review language. Thus, an analysis of even one very specific online discourse community yields 
analysis that transcends the actual content. In this research, a genre analysis of online reviews for fuzz pedals can raise concerns pertaining to all online reviews in general.

The research for this project started with a pleasurable hobby. Guitar effects pedals are a guilty pleasure for this writer, and after many sessions of reading "expert" online effects pedal reviews, I began to wonder about the production of the reviews and their legitimacy, as there is no vetting process to making an "expert" online review.

The reviews are important in that the online appraisal of a fuzz pedal may be the only authoritative source to be found by a consumer. A stellar review can therefore increase the sales of a fuzz pedal as a consumer electronic product. Furthermore, consumer electronics are a fact of contemporary life, and the cheap manufacture and quality of some fuzz pedals can lend itself to a somewhat pre-packaged and disposable online review. However, when an analysis of several electronic fuzz pedal "expert" online reviews reveal generic characteristics which seem too similar in their "prototypicality," (a defining point for genre as mentioned by Swales, 1990) questions arise as to the authenticity of the reviews. Further, Swales (2004) also mentions these issues (among others) of author agency as another issue concerning genre that was brought forth by Bhatia (1993).

Just as Swales (2004) modifies the original Moves Analysis (1990) to provide more nuance to the results, so does this paper seek to further refine Swales technique, (admittedly in a somewhat broad and cavalier manner) to the lexical level in an attempt to remove any bias. In this manner of focusing on the lexical qualities of the online reviews, the very similar qualities of the "experts" may be revealed.

\section{Hybrid Genres}

According to Johns et al. (2006), genres assist people in completing tasks by using particular language in particular contexts and harnessing the format of the context to give information in textual form. Johns et al. (2006) also noted that genre examples typically vary, even within the same genre and explained that a genre may vary from a typical template to agree with particular sentiments of those who are judging the genre. Thus, online reviews of fuzz pedals work with certain themes that reveal textual context related to the fuzz pedal reviewer discourse community, while also maintaining particular generic moves, which are expected from the review format. This blending of genre forms is a natural occurrence as according to Bhatia and Salmani (2015), even though in academic professional contexts and in Swales (1990) there is focus on pure genres, hybrid genres are the norm and the actual existence of a pure genre is doubtful. Although Bhatia and Salmani (2015) focus on genres for English for Specific Purposes (ESP), genre analysis can be applied to digital media text, and these digital media texts allow for new types of analysis. Sheperd \& Watters (1998) predicted this type of new digital media format as a meta-genre and coined the term "cyber genre." Although this term seems almost dated now due to the "cyber" moniker, at the time of coining it was an accurate forecasting for the format of online digital media genres. In essence, all genres, even those of the digital arena, are of a hybrid quality. 


\section{Authorial Power with Occluded Genres}

Foucault (1972), who originated the term "social authorship," raised a set of very important questions: "...who is speaking? Whom among the totality of speaking individuals, is accorded the right to use this sort of language? Who is qualified to do so?" (p. 50). This line of thought yields the fundamental question of who within a discourse community is a perceived expert. In addition, why his or her voice is able to rise above the others and be "the expert." Why are some within an online community chosen to write reviews of fuzz pedals (an enviable occupation for some within the discourse community) and have them posted online, while the bulk of the discourse community must be satisfied with online forums and user-generated reviews? Who has had access to the logistical workings of testing, writing and producing an online review for a consumer electronics product?

Authorship of online reviews easily lends itself to the subject of occluded genres, wherein invested discourse community players have a part in the production, distribution and promotion of a consumer product without their exact roles and relationships ever being made clear. Although the writers of the reviews are sometimes named, their specific qualities as experts in reviewing are never put to the test. As far as one can tell, reviewers buy or are given a pedal; the pedal is personally tested by the reviewers, and an online review is written and posted onto the internet. How the reviewers receive the pedal and access to the online submission format is hardly ever stated (although some reviewers may include a quick biography and rationale for having a certain pedal, or be obviously employed by a larger online presence).

In essence, expert online fuzz pedal reviews work similarly to online book or movie reviews, or even consumer electronic or musical instrument reviews. A new product or media is acquired and reviewed by an "expert." However, the genre chain is never revealed or made easy to be revealed, so occlusion of actors within the production of the online reviews is the norm. The entertaining and informative quality of the reviews may lead some to never question the forces at work behind the reviews. The fact that fuzz pedals are most usually given a positive review with very little negative language also strengthens the argument of an occluded genre chain that may involve the manufacturers. Thus, there is the question of who gives authority to the expert?

With regards to the samples used herein, the fuzz pedals could be provided pro bono to the expert reviewers and this could have the effect of skewing data to the positive and away from the negative. This is a direct example of an occluded genre chain with a hierarchical power structure. According to Bhatia (as cited by Johns, 2008), this would become part of a chain of Promotional Genres.

\section{Subconscious Marketing}

Fuzz pedals are non-essential electronic consumer products, and online reviews are, according to Mudambi and Schuff (as cited in Riasanow, Ye, \& Goswami, 2015), "peer generated product evaluations posted on company or third party websites" (p. 3309). Some of these "peer generated" product evaluations delve into stylistically surreal written territories that appeal to human senses. 
Botti and McGill (as cited in Kronrod \& Danziger, 2013) suggested, "hedonic consumption is more 'affectively rich' than utilitarian consumption; therefore, preferences for hedonic goods are emotionally driven, whereas those for utilitarian goods are cognitively driven" (p. 726). Thus, appeal to human senses for fuzz pedals appears to be the norm, as will be discussed below. The reviewers' use of sensory appeal allows fuzz pedals to be marketed as a hedonic product attaching psychological feelings of pleasure to the product.

Subconscious marketing extends beyond just the sensory however, as a further subliminal effort to impress consumers is stated by Connors, Mudambi and Schuff (2011) who found that reviews with a self-described "expert" were deemed more helpful for consumers, which could result in online reviewers feeling the need to selfidentify as experts under false pretenses. Further, Connors, et al. (2011) stated that content is more important for consumers than a carefully unbiased or balanced review.

\section{Manipulation of Online Digital Reviews}

Expert online reviews of fuzz pedals are a new genre. According to Crystal (2007), "New genres add to the expressive potential of a language...And it is the same for all new genres. They allow authors to manipulate them in creative ways" ( $\mathrm{p}$. 160). This is not to say that every new review written by an author is in itself a new genre, rather, expert online electric guitar fuzz pedal reviews satisfy the qualities of a genre as outlined by Swales (1990).

As Swales (2004) points out, genre conventions affect reader interpretations, even in the business realm. Unsurprisingly, it did not take marketers very long to independently realize the very same conventions for their own aims, and as Huang, Yang, Lin and Shih (2012) have noted, dishonest companies consciously work to manipulate online reviews to garner positive electronic word of mouth (eWOM) which in turn increases product sales. Figure 1 provides reference of the position of expert online fuzz pedal reviews as regards to other online review genres.

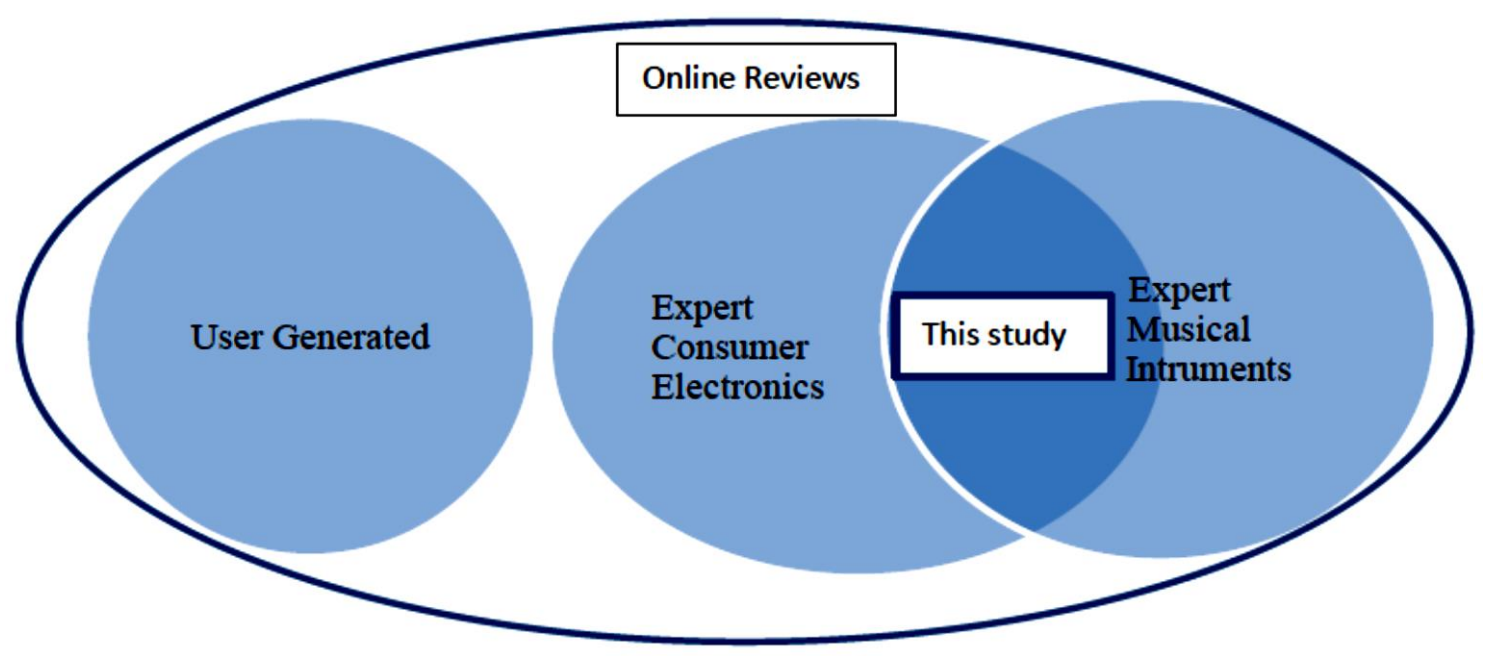

Figure 1: Simplified relationship of expert online fuzz pedal reviews to other online reviews 
As Figure 3 shows, this study is situated at a meeting point between two larger areas of expert online reviews, that of consumer electronics and musical instruments. User generated reviews, which are arguably more "honest" since they appear to be a direct source of feedback from consumers, are not included in the realm of expert online reviews. The manipulation of user-generated reviews, I feel, would be a further interesting phenomenon to study, as it could reveal extremely overt manipulation of consumer voices for marketing purposes.

\section{Methods}

Ten samples of recent (20102015) expert online reviews of guitar fuzz pedals were chosen at random from top picks chosen by Google. The phrase typed in the Google search box query was "online fuzz pedal reviews." The available selection was limited in several ways. This type of expert online review is a very recent genre, so online textual samples older than ten years tended to be of a very modest variety with not much text and were disregarded for this study. Most likely the paucity of expert online reviews for fuzz pedals is a result of the continued existence of major print guitar magazines in which guitar effects box reviews were (and still are) typically found in a print format. The Google search immediately brought up certain guitar magazine online sites, in this case premierguitar.com, guitarplayer.com and guitarworld.com, Also the boutique quality of the genre in which guitar effects boxes are made and distributed lends itself to a more WOM marketing culture as opposed to those for a mass produced item with millions of units in contention. Since effects pedals are not typically made for the masses as a consumer electronics product, textual online reviews are not that easy to find in digital formats. Online video reviews are the norm.

The text portions of the online reviews were cut and pasted into Microsoft word in both .docx and .txt formats into matching fonts for ease of readability, and then analyzed using a Modified Move Analysis after the manner of Move Analysis as detailed by Swales (1990). Modified Move Analysis is here defined as using the textual mining features of a Move Step Analysis and modifying the Move Step dynamic to focus on determined lexicographic parameters. The lexicographic parameters are not a foregone conclusion, but are realized as categories (based on the lexical results of the findings) at the result of the analysis.

The reason for the analysis was to fully gauge the depth of textual patterns in the ten samples of online reviews of fuzz pedals. This textual depth could reveal what generic textual features were relevant to online readers and thus reveal what is beyond the "prototypicality" of the genre. Too much similarity would reveal stylistic issues bordering on plagiarism ('generic plagiarism'?). Too little similarity would reveal a break from the genre norms. In addition, the research met the need for analysis of a new computerbased online technological feature, which according to Swales (2004), "... are contentious in terms of whether their effects are wholly positive" (p. 4), but which now, twelve years after Swales' Research Genres, seem to be in the process of commodification. Thus, even though a technology seems to be performing a valid function, in this case, the freedom of the internet is allowing multiple voices to flesh out the genre of expert online reviews, and so there 
could be several occluded players as parts of genre chains (marketers, product managers, salespeople) who are behind the scenes, anonymously manipulating the online review content and affecting the language of the reviews. The use of a Modified Move Analysis, instead of relying on set Moves as in Swales (1990, 2004), reduces any bias that may occur. The Modified Move Analysis used only found-in-the-text lexicographic parameters as indicators of Moves. The Moves, Move Labels, and Comments/Examples provided below in Table 1 were created after the textual analysis and were not the result of any pre-established categories as may be found in a more traditional Move Analysis.

Appendix A provides all ten samples used in this study.

\section{Limitations}

The reported study has two limitations. First, the small sample of reviews $(\mathrm{N}=10)$ limited the amount of data analyzed. Second, the ten samples were only from two countries, the United States and the United Kingdom. As Standard Englishes are the dominant languages in both of those countries, whatever lexicographic parameters that might be identified by the analysis were defined by the Englishes used in the US and UK.

\section{Results}

This section provides the results of the analysis. One of the major findings of the study was that the reviewers adopted an almost overly enthusiastic approach to the quality of the pedals.

Table 1 provides the Moves, Move Labels, and Comments/ Examples that were established from the genre analysis of the online fuzz pedal reviews.

Table 1. Modified Move Analysis of ten samples (without regard to ordering within the texts).

\begin{tabular}{|c|c|c|}
\hline Move \# & Move Label & Comments/ Examples \\
\hline 1 & Video/Visual Aid/Web Link & $\begin{array}{l}\text { All samples provided an embedded video, video link, } \\
\text { and/or photograph of the fuzz pedal along with a link } \\
\text { to the company webpage for more viewing options. In } \\
\text { addition, imperative constructions were the norm. } \\
\text { - } \quad \text { Visit Electro Harmonix ... } \\
\text { - } \quad \text { Visit Zvex for more infor... } \\
\text { - } \quad \text { - thetonegod.com } \\
\text { - } \quad \text { CONTACT analogman.com } \\
\text { - } \quad \text { Here's a } 2010 \text { video of ... } \\
\text { - } \quad \text { rotosound.com } \\
\text { - } \quad \text { Watch our video review } \\
\text { - } \quad \text { Check out the official video demo: } \\
\text { - } \quad \text {...visit JHS pedals for further details. }\end{array}$ \\
\hline
\end{tabular}


Specifications/Construction Features
Nine of the ten samples provided allusion to a past fuzz pedal, fuzz sound, famous band or famous guitarist.

- With a legacy dating back over 40 years...

- ...fuzz distortion pedals of the past 20 years.

- In $2008 \ldots$

- $\quad$ SOUNDS Inspired by the Strawberry Alarm Clock's seminal psychedelic fuzz soaked classic...

- Here's a 2010 video of Gilbert...

- $\quad$ The fuzz effect was used by iconic guitarists...

- Few names have more renown...

- Being relatively new...

- Inspired by the popular Beatle's tune...

All samples included at least one reference to the physical design or technical specifications of the pedal.

- Powered by 9 volt battery...

- 2 ultra rare 1956 Amperex black glass germanium transistors.

- ...a sturdy black metal chassis...

- $\quad$ The chassis and external components are rugged...

- $\quad$ KNOBS Volume, Fuzz, Buzz, internal trimpot

- ...studio grade Carling footswitches

- ...a roar/rumble switch...

- ...battleship/tackle-box gray hammerite finish

- ...single foot switch...

- .... a Hi-Pass switch...

All samples effusively described the acoustic qualities upon the electric guitar's tone after using the fuzz pedal.

- $\quad$... a world of extreme fuzz textures...

- ...an infinite palette of sounds.

- .... a tremendous range of distortion sounds...

- ... a crisp and well defined high-end.

- A very impressive array of fuzzy flavors.

- ...a hands down hit.

- ...monstrous tone...

- $\quad$...rich, growling power-chord potency.

- ...versatile and great sounding fuzz tones... 
- $\quad$...spitting fuzz...

Positive Judgment

Negative Judgment (of a specific feature)
Eight of the ten samples provided a form of positive judgment on the pedal.

- Overall-Rating-5.0 (used twice)

- Buy if...you want a tremendous range...

- Pros: An extremely high quality...

- Who's it for? Players who want...

- ...makes this ideal for ...

- Pros: Authentic vintage ...

- $\quad$...the versatility and quality of this pedal more than makes up for...

Seven of the ten samples provided a form of negative judgment on some feature of the pedal, but never on the pedal as a whole.

- It's nearly perfect...

- ...plenty of sweet spots that can be lost...

- $\quad$ Skip if...your distortion needs can be met...

- Cons: The Fuzz Head is quite expensive...

- ....are not as convincing as I'd hope...

- Could be more responsive to...

- While the price tag can be a bit over the top...
Table 1 contains several notable findings. Move 1 (Video/Visual Aid/Web Link), appealing to the visual, is now a necessary component of the internet culture for these online reviews. Currently, the internet is primarily a visual medium. From what can be gleaned from the online sources and the text themselves, fuzz pedals are readily discussed as having a "boutique" quality (even though some pedals are factory produced and some are handmade) and visual appeal is a prime factor in their design and construction. Earlier models were of a boxy mechanical/utilitarian design, while today, the boxy design is still a necessary functional shape for housing electrical circuits, but some models are overly engineered, designed or even hand painted. Within this discourse community (and arguably even outside of the community), these pedals have become heirlooms, cherished for their aesthetic qualities, as evidenced by their constant presence on www.ebay.com and such sites as www.effectsdatabase.com.

Move 2 (Historical Allusion) harkens to the raw Rock and Roll roots of the fuzz sound. Arguably, the first fuzz/distortion sound came from overdriven or even purposely malfunctioning equipment, (Hitchcock \& Sadie, 1986). Being perceived as "vintage" may increase a pedal's perceived authenticity, and hence marketability, as all older members within the discourse community would understand the historic underpinnings of 
certain features, looks, and sounds of particular pedals. Some pedals, such as the Tone Bender and the Big Muff Pi, retain a legendary status because of these historic connections. Further, the main components of an analog fuzz pedal, although usually updated with improved hardware, are relatively unchanged from the earliest pedals of the 1960s, hence the appearance in Sample Text 2 of " 2 ultra rare [sic] 1956 Amperex black glass germanium transistors." While these technological elements arguably do not create effects that are different to an average person's, or even a musician's, hearing, according to Hunter (2004) these historic-tech elements lend an aura to the fuzz pedals which increases their value both monetarily and in terms of collectability. An even rarer and more valuable find would be an authentic and untouched vintage pedal within its original packaging, in mint condition, or a pedal with bona-fide provenance as having been part of a famous musician's gear.

This leads to more technical product advertising in Move 3 (Specifications/Construction Features) as the fuzz pedals are shown as having engineered mechanical "specs," much as one would see for an automobile or other vehicle. Again, there is appeal to the senses and, in some instances, the aesthetics of the physical design.

It is in Move 4 (Sonic Qualities) where the real expository qualities of the online writers, begin to be heard. There are multitudes of sensory descriptors that characterize the sonic qualities of the pedals and increase their WOM legend, first within this discourse community, and then to the larger world of music listeners, perhaps. Table 2 provides some examples of these "target sensory appeals."

Table 2. Sensory appeal of the sonic qualities in sample texts.

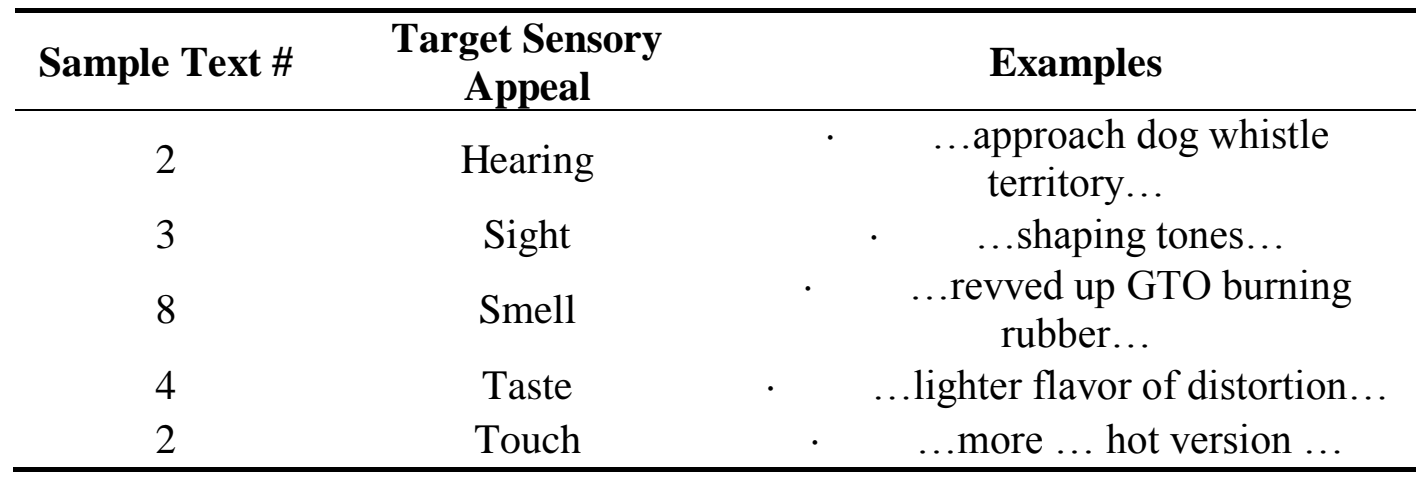

Interestingly, all of the sensory appeals in Table 2, with the exception of "Hearing," are to be found, according to Paradis and Eeg-Olofsson (2013), in the genre of wine reviews. Similar appeals to the sensory (Krishna, 2011) are well known in marketing and recognized as categories of audition, vision, taste, olfaction (smell), and haptics (touch).
Moves 5A (Positive Judgment) and 5B (Negative Judgment [of a specific feature]) were a dual move in some instances. For instance, "Pros Cons", or "Buy if - Skip if." Other samples had no verdict, just praise. Surprisingly, there were never any harsh negative verdicts. Almost all negative statements were hedged, either with a modality, such as could, much, or would have, or with a statement about the expensive price of the pedal. 
Thus, with expert online fuzz pedals reviews there are variations on a generic 'theme,' as there are established Moves which can be discerned, but no single 'blue print' or 'template' which is wholly adhered to.

\section{Discussion}

\subsection{Negative Judgments}

There are several reasons why the fuzz pedals were not given harsh negative judgments. First, the pedals could be given by the company to the reviewer, and therefore harshly negative reviews could result in less work for a pedal reviewer and also fewer pedals that the reviewer will get to keep. Second, the pedals are loaned to the reviewer and still a harshly negative review will do nothing but detract from a reviewer's reputation and again will result in fewer writing assignments. Third-and this is the most probable theory when all factors are considered - the reviewers of the fuzz pedals are musicians (they need to at least "play" electric guitar) who know their audience and also true pedal connoisseurs, as evidenced by their knowledge of the technical terms such as fuzz, distortion, gain, attack, bypass, input, output used by the discourse community. Whether the pedals are given or borrowed, reviewers realize the pedals are (to the discourse community) usually high quality pieces, and in some sense, works of art, so to use overtly negative attitudes in their judgments would be akin to "striking a bad chord" within their discourse community. Since this study did not analyze cheaper "clone" or "copy" online fuzz pedal reviews, the quality of the pedals was decent to high, and thus, negative comments were minimal.

Other pedals from less reputable manufacturers may invoke wrathful judgment from some within the discourse community, most likely for their build quality, and not the sonic quality, as even the worst sound can be tweaked within a "pedal chain," or through another amplified device, to transform it into something sonically pleasing to someone, somewhere. However, to make a sound, at a bare minimum, there has to be a signal going through a working circuit. Thus a nonworking, and therefore a silent fuzz pedal, at any price point, would be the one with the most negative features.

Further, the almost non-existent use of negative qualities for the fuzz pedals as evidenced above in Move \#5b alludes to a lack of deep criticism for the pedals. Particular features are given a few negative words, but the overall lack of negative criticisms proved a "cookie-cutter" quality to the writing of the reviews and further points to a commodification of the genre. There are no real critical views, only an emphasis on positive points that in turn would assist in the sales of the pedals.

Finally, members of this discourse community could find a different place to vent extremely negative comments in online forums, such as www.thegearpage.net or http://www.harmonycentral.com/forum/ forum/guitar/acapella-29 and there are websites such as www.Amazon.com wherein user-generated formats allow anyone to leave a review and a star rating. There are a number of these online forums and now major-name websites to cater to the passions of enthusiasts. It is this writer's belief that further genre-analysis of these new digital formats would yield rich and interesting results. A possible glitch in this approach may be further commodification of these new genres 
before they are even seen outside of their specific discourse communities.

\subsection{Hybrid Genres}

Hybrid genres are the result of the moving away from the perception of pure genres toward a more nuanced understanding of the concept. Definition of what is pure, and therefore may be a pure genre, seems to be in an academic state of flux as of this writing. The hybrid genre is the norm. For this reason, it seemed sensible for a hybrid Move Analysis to be utilized for this particular genre. I used the method of Moves Analysis and adapted it to discover lexicographic qualities in the texts. The particular Moves which revealed themselves from the texts are content-specific for this particular hybridized genre. Other future hybrid genres will most likely require their own form of hybrid Move Analysis, perhaps based on my findings. It is this writer's intent to merely set in motion a new approach for a new form of textual technology, based on an already defined textual tool. Thus, a hybridized move analysis seemed the best way to move forward.

\subsection{Authorial Power with Occluded Genre Chains}

Authorial power and genre occlusion are the status quo in the expert online review as there are very limited sources to identify all the players and participants. In addition, there is still the question of who will have the authority to grant access to online content. As this study has made clear, there are no clear definitions of who can be an online "perceived expert." Any company with the money and willingness to make an online review can do so.
Perhaps the future holds a more transparent form of genre clarity, which can work for the digital realm, instead of the more likely scenario of total obfuscation of online content production through impenetrable digital genre chains. Of course, the Internet can be a haven for anonymity. That anonymity may be at risk if online content producers must always be revealed.

\subsection{Subconscious Marketing}

Subconscious marketing will continue online as well as a caveat emptor attitude wherever there is money to be made. However, there may be solace with the fact that younger generations are increasingly tech savvy and may be immune to the Pavlovian effects of online marketing techniques.

As this study demonstrates, sensory appeal is very much a part of online fuzz pedal reviews. It involves sense perceptions that are not usually associated with the fuzz pedals being reviewed. These sense perceptions help to lend a hedonistic air and "rock sensibility" to fuzz pedals. These feelings appeal to underlying psychological assumptions of pleasure and, ultimately, help to sell the fuzz pedals.

\subsection{Manipulation of Online Digital Reviews}

Manipulation of online digital technologies is probably the most serious topic of those mentioned here. As technology has always been a dualedged sword for human endeavors, it will most likely continue to be so. In one sense, a massive outsourcing of information is incredibly useful for the progress of society as a whole. The Internet is a revolution in terms of information sharing. However, control 
of information may result in the control of larger societal structures related to monetary and political power. Even this study, with its limitations, reveals the possible control of information for monetary power, in this case, to increase WOM sales of certain fuzz pedals through expert online reviews.

\section{Further Research}

Ideas for further research into online reviews are abundantly clear and fertile in this golden age of Internet usage and online accessibility. A textual generic study could be modified to identify speech in YouTube videos in which other products are reviewed. Take the case of https://www.youtube.com/user/gearman ndude/featured, where the only intent of the producer of the videos is to acquire electric guitar effects pedals (and sometimes other musical gear) and make a video review of the pedals. This channel has over 58,000 followers as of this writing. The WOM language of these videos seems ripe for advertising consumption. As stated by Simonson and Rosen (2014, online source)," Instead of measuring individual consumers' preferences, satisfaction, and loyalty, marketers should redirect resources to the systematic tracking, coding, and quantifying of information from review sites, user forums, and other social media."

Further investigations could be made into how and why the reviewers were chosen and if there are occluded genre chains which affect the choice of reviewers for particular pedals. In addition, research could focus on how involved in the review process are the companies that produce the fuzz pedals. Are participants in online forums and user-generated online reviews truly anonymous unpaid reviewers or are they also part of an occluded genre of product advertising? Huang et.al. (2012) found evidence of online manipulation of online reviews after a computer malfunction at Amazon in 2004, and real names behind online nicknames revealed the true writers to be fraudulent and misrepresenting.

\section{References}

Bakhtin, M. M. (1986). Speech Genres and Other Late Essays.

Bhatia, V.K. (1993). Analysing genre: Language use in professional settings. London: Longman.

Bhatia, V. K. (1997). The power and politics of genre. World Englishes, 16(3), 359-371.

Bhatia, V. K., \& Salmani Nodoushan, M. A. (2015). Genre analysis: The state of the art. International Journal of Language Studies, 9(2).

Bhatia, V., Sánchez, H. P., \& PerezParedes, P. (Eds.). (2011). Researching specialized languages. Amsterdam, NLD: John Benjamins Publishing Company. Retrieved from http://0www.ebrary.com.library.s vsu.edu.

Connors, L., Mudambi, S. M., \& Schuff, D. (2011, January). Is it the review or the reviewer? A multi-method approach to determine the antecedents of online review helpfulness. In System Sciences (HICSS), 2011 44th Hawaii International Conference on (pp. 1-10). IEEE.

Crystal, D. (2007). Words, words, words. Oxford University Press.

Foucault, M. (1972). The archaeology of knowledge \& the discourse on language. New York: Pantheon 
Books. Retrieved from https://monoskop.org/images/9/90 /Foucault_Michel_Archaeology_o f_Knowledge.pdf.

Hitchcock, H. W., \& Sadie, S. (Eds.). (1986). The new Grove dictionary of American music. Macmillan.

Huang, Y. K., Yang, W. I., Lin, T. M., \& Shih, T. Y. (2012). Judgment criteria for the authenticity of internet book reviews. Library \& Information Science Research, 34(2), 150-156.

Hunter, D. (2004). Guitar Effects Pedals-The Practical Handbook. Hal Leonard Corporation.

Johns, A. M. (2008). Genre awareness for the novice academic student: An ongoing quest. Language Teaching, 41(02), 237-252.

Johns, A. M., Bawarshi, A., Coe, R. M., Hyland, K., Paltridge, B., Reiff, M. J., \& Tardy, C. (2006). Crossing the boundaries of genre studies: Commentaries by experts. Journal of Second Language Writing, 15(3), 234-249.

Krishna, A. (Ed.). (2011). Sensory Marketing: research on the sensuality of products. Routledge.

Kronrod, A., \& Danziger, S. (2013). "Wii Will Rock You!" The Use and Effect of Figurative Language in Consumer Reviews of Hedonic and Utilitarian Consumption. Journal of Consumer Research, 40(4), 726-739.

Paradis, C., \& Eeg-Olofsson, M. (2013). Describing sensory experience: The genre of wine reviews. Metaphor and Symbol, 28(1), 2240.

Riasanow, T., Ye, H., \& Goswami, S. (2015, January). Generating Trust in Online Consumer Reviews through Signaling: An Experimental Study. In System Sciences (HICSS), 2015 48th Hawaii International Conference on (pp. 3307-3316). IEEE.

Shepherd, M., \& Watters, C. (1998, January). The evolution of cybergenres. In System Sciences, 1998, Proceedings of the ThirtyFirst Hawaii International Conference on (Vol. 2, pp. 97109). IEEE.

Simonson, I., \& Rosen, E. (2014). What marketers misunderstand about online reviews.

Swales, J. (1990). Genre analysis: English in academic and research settings. Cambridge University Press.

Swales, J. (2004). Research genres: Explorations and applications. Cambridge University Press. 